\title{
Hemangiomatosis with Thrombocytopenia
}

National Cancer Institute

\section{Source}

National Cancer Institute. Hemangiomatosis with Thrombocytopenia. NCI Thesaurus.

Code C3821.

A cavernous angiomatosis associated with the destruction of platelets, resulting in thrombocytopenia. 